\title{
Risk adjusted and population based studies of the outcome for high risk infants in Scotland and Australia
} International Neonatal Network, Scottish Neonatal Consultants, Nurses Collaborative
Study Group
Keywords: neonatal intensive care units; mortality; very preterm infants; very low birthweight infants

Objectives-To compare outcomes of care in selected neonatal intensive care units (NICUs) for very low birthweight (VLBW) or preterm infants in Scotland and Australia (study 1) and perinatal care for all VLBW infants in both countries (study 2). Design-Study 1: risk adjusted cohort study; study 2: population based cohort study.

Subjects-Study 1: all 2621 infants of $<1500$ g birth weight or $<31$ weeks' gestation admitted to a volunteer sample of hospitals comprising eight of all 17 Scottish NICUs and six of all 12 tertiary NICUs in New South Wales and Queensland in 1993-1994; study 2: all 5986 infants of 500$1499 \mathrm{~g}$ birth weight registered as live born in Scotland and Australia in 1993-1994.

Main outcomes-Study 1: (a) hospital death; (b) death or cerebral damage, each adjusted for gestation and CRIB (clinical risk index for babies); study 2 : neonatal (28 day) mortality.

Results-Study 1. Data were obtained for 1628 admissions in six Australian NICUs, 775 in five Scottish tertiary NICUs, and 148 in three Scottish non-tertiary NICUs. Crude hospital death rates were $13 \%, 22 \%$, and $22 \%$ respectively. Risk adjusted hospital mortality was about $50 \%$ higher in Scottish than in Australian NICUs (adjusted mortality ratio $1.46,95 \%$ confidence interval (CI) 1.29 to $1.63, \mathrm{p}<0.001)$. There was no difference in risk adjusted outcomes between Scottish tertiary and nontertiary NICUs. After risk adjustment, death or cerebral damage was more common in Scottish than Australian NICUs (odds ratio $1.9,95 \%$ CI 1.5 to 2.5 ). Both these risk adjusted adverse outcomes remained more common in Scottish than Australian NICUs after excluding all infants $<28$ weeks' gestation from the comparison. Study 2 . Population based neonatal mortality in infants of 500-1499 $\mathrm{g}$ was higher in Scotland (20.3\%) than Australia $(16.6 \%)$ (relative risk 1.22 , $95 \%$ CI 1.08 to $1.39, p=0.002)$. In a post hoc analysis, neonatal mortality was also higher in England and Wales than in Australia. Conclusions-Study 1: outcome was better in the Australian NICUs. Study 2: perinatal outcome was better in Australia. Both results may be consistent, at least in part, with differences in the organisation and implementation of neonatal care.

(Arch Dis Child Fetal Neonatal Ed 2000;82:F118-F123)
Scotland and Australia have contrasting models of organisation for neonatal intensive care. In 1993 and 1994, nearly all infants who received neonatal intensive care were treated in 17 tertiary and non-tertiary centres in Scotland and in 23 tertiary centres in Australia. Average annual numbers of deliveries per neonatal intensive care unit (NICU) were therefore less than 4000 in Scotland ${ }^{2}$ and over 10000 in Australia, assuming 65000 and 250000 annual births, respectively. ${ }^{3-5}$ In Australia a greater proportion of consultants who supervise NICUs are full time neonatologists, and neonatal specialist training for nurses is longer, typically requiring a year compared with six months in the United Kingdom. Official recommendations for nurse infant staffing ratios also differ: the British Association of Perinatal Medicine has recommended up to two ventilated infants per nurse each shift, ${ }^{67}$ whereas the Australian Health Ministers' Advisory Council stipulates only one ventilated infant per nurse. ${ }^{8}$

\section{STUDY 1}

To investigate whether these models of organisation may be associated with differences in outcome, we prospectively compared risk adjusted hospital mortality in very low birthweight (VLBW; < 1500 g) or very preterm (<31 weeks' gestation) infants in selected NICUs in each country. The main aims were to compare outcomes between countries and types of NICU, adjusting for risk using gestation and CRIB (clinical risk index for babies) scores. ${ }^{9}$ CRIB is an index of clinical risk and illness severity in infants of $<1500 \mathrm{~g}$ birth weight or < 31 weeks' gestation, which has been validated as more accurate than birth weight or gestation in assessing initial risk of hospital mortality among infants admitted for neonatal intensive care. ${ }^{10-15}$

Although the most valid measure of the outcome of care after admission to NICUs is hospital mortality, adjusted for clinical risk and initial illness severity, appropriate data for risk adjustment were not routinely collected when this study was planned. Risk adjusted mortality could only be measured in those units that accepted the invitation to participate in the project. This was therefore not a population based comparison and selection bias could not be excluded. 
Table 1 Hospital organisation, clinical characteristics, and unadjusted outcomes for 2612 very low birthweight (VLBW) or preterm infants admitted to Scottish and Australian neonatal intensive care units in 1993 and 1994

\begin{tabular}{|c|c|c|c|c|}
\hline & Scottish tertiary centres & $\begin{array}{l}\text { Scottish non-tertiary } \\
\text { centres }\end{array}$ & $\begin{array}{l}\text { Australian tertiary } \\
\text { centres }\end{array}$ & p Value \\
\hline Number of centres & 5 & 3 & 6 & \\
\hline Total VLBW/preterm infants admitted & 827 & 156 & 1629 & $0.0001 \dagger$ \\
\hline Number of intensive care cots $\star$ & $10(10,20)$ & $4(4,6)$ & $20(13,20)$ & $0.0001 \dagger$ \\
\hline Annual volume of VLBW/preterm infants per centre & $104(65,121)$ & $30(30,31)$ & $297(255,422)$ & $0.0001 \dagger$ \\
\hline Gestation (weeks)^ & $29(27,31)$ & $29(27,31)$ & $29(27,30)$ & $0.016 \dagger$ \\
\hline Birth weight $(\mathrm{g})^{\star}$ & $1180(900,1400)$ & $1171(880,1388)$ & $1166(908,1375)$ & $0.665 \dagger$ \\
\hline Five minute Apgar score ${ }^{\star}$ & $9(7,9)$ & $9(7,9)$ & $8(7,9)$ & $0.0001+$ \\
\hline Worst base excess in first 12 hours $(\mathrm{mmol} / \mathrm{l})^{\star}$ & $-5(-8.45,-2)$ & $-5(-8.85,-2.6)$ & $-4.05(-6.7,-1.9)$ & $0.0001 \dagger$ \\
\hline Maximum $\mathrm{FIO}_{2}$ in first 12 hours ${ }^{\star}$ & $0.5(0.25,0.77)$ & $0.5(0.3,0.8)$ & $0.45(0.26,0.75)$ & $0.449 \dagger$ \\
\hline Minimum $\mathrm{FIO}_{2}$ in first 12 hours ${ }^{\star}$ & $0.21(0.21,0.38)$ & $0.25(0.21,0.4)$ & $0.25(0.21,0.4)$ & $0.0003 \dagger$ \\
\hline CRIB score ${ }^{\star}$ & $2(1,6)(\mathrm{n}=761)$ & $3(1,7)(\mathrm{n}=136)$ & $2(1,6)(\mathrm{n}=1476)$ & $0.410 \dagger$ \\
\hline Hospital deaths (\%) & $172 / 775(22 \%) \ddagger$ & $33 / 148(22 \%) \ddagger$ & $216 / 1628(13 \%)$ & $<0.0001$ \\
\hline Major brain damage in infants who had ultrasound scanning (\%) & $87 / 734(12 \%)$ & $12 / 151(8 \%)$ & $118 / 1480(8 \%)$ & $<0.00019$ \\
\hline
\end{tabular}

${ }^{\star}$ Median (interquartile range).

†From Kruskal-Wallis test for three independent samples.

¥If all missing cases in Scotland had survived, the hospital mortality for Scottish neonatal intensive care units would be $20.9 \%$. If the missing case in Australia had died, the hospital mortality rate would be $13.3 \%$. The difference between these rates remains statistically significant.

ॠFrom $\chi^{2}$ test for $2 \times 2$ table comparing Scottish and Australian infants.

\section{STUDY 2}

Population based 28 day neonatal mortality statistics were available for all infants born alive and weighing between 500 and $1499 \mathrm{~g}$, as they are a statutory requirement in Scotland and Australia. However, the neonatal death rate is a measure of perinatal rather than neonatal outcome, as it reflects both obstetric and neonatal care. ${ }^{16}$ Bearing in mind this caveat, we compared national neonatal death rates in liveborn infants of 500-1499 $\mathrm{g}$ during the same period. As neonatal care is an important component of perinatal care, we predicted that, provided that the sample of Scottish and Australian NICUs selected in study 1 were not atypical of each country, any difference in risk adjusted mortality between them would be reflected by a parallel difference in population based neonatal mortality.

\section{Methods}

STUDY 1

The risk adjusted cohort study included all 2612 infants of less than 31 weeks' gestation or less than $1500 \mathrm{~g}$ birth weight admitted between 1 January 1993 and 31 December 1994 to 14 Australian or Scottish NICUs which agreed to provide a simple minimum dataset over this period. They comprised six of all 12 Australian NICUs in Queensland and New South Wales (Kirwan, Townsville; Mater and Royal Women's, Brisbane; John Hunter, Newcastle; Westmead and King George V Hospitals, Sydney), the five designated tertiary Scottish NICUs (Aberdeen Maternity Hospital; Queen Mother's Hospital for Sick Children, Yorkhill, Glasgow; Royal Maternity Hospital, Glasgow; Ninewells

Table 2 Proportions of extremely low birthweight (500-999 $\mathrm{g}$ ) compared with very low birthweight (500-1499 g) infants in the study cohort and national populations in each country in 1993 and 1994

\begin{tabular}{|c|c|c|c|c|c|}
\hline & $\begin{array}{l}\text { Infants } \\
500-999 \mathrm{~g} \\
\text { birthweight }\end{array}$ & $\begin{array}{l}\text { Infants } \\
500-1499 \mathrm{~g} \\
\text { birthweight }\end{array}$ & $\begin{array}{l}\% \text { infants } \\
500-999 \mathrm{~g} \\
\text { birthweight }\end{array}$ & $\chi^{2}$ & p Value \\
\hline \multicolumn{6}{|l|}{ Scotland } \\
\hline $\begin{array}{l}\text { Study cohort (8 intensive } \\
\text { care units) }\end{array}$ & 338 & 867 & 39 & & \\
\hline All live births & 458 & 1216 & 38 & 0.37 & 0.54 \\
\hline \multicolumn{6}{|l|}{ Australia } \\
\hline $\begin{array}{l}\text { Study cohort (6 intensive } \\
\text { care units) }\end{array}$ & 515 & 1449 & 36 & & \\
\hline All live births & 1820 & 4770 & 38 & 0.1 & 0.75 \\
\hline
\end{tabular}

Hospital and Medical School, Dundee; Simpson Memorial Maternity Pavilion, Edinburgh), and three of the 12 non-tertiary Scottish NICUs (Southern General Hospital, Glasgow; Raigmore Hospital, Inverness; Forth Park Hospital, Kirkcaldy). The primary outcome was hospital mortality before hospital discharge. Infants admitted to neonatal units with inevitably lethal congenital malformations were excluded from all stages of the analysis. The severity of other congenital malformations were subsequently coded in three categories ${ }^{9}$ as acutely life threatening, not acutely life threatening, or absent or trivial, by a neonatologist unaware of the country or hospital. A secondary outcome was death or major cerebral damage on ultrasound, defined as cystic leucomalacia, porencephalic cyst, or parenchymal echodensities observed in either hemisphere. ${ }^{9}$ Measures of clinical risk and illness severity were abstracted from notes after discharge. CRIB includes three clinical components, birth weight, gestation, and severity of congenital malformation, and three measures of illness severity up to 12 hours from birth, maximum and minimum appropriate fraction of inspired oxygen, and worst base deficit. ${ }^{9}$ CRIB scores were calculated for every admission, from data up to 12 hours from birth or until death if sooner. Outcomes of transferred infants were attributed to the hospital providing the longer period of care between 12 and 72 hours from birth.

\section{STUDY 2}

National neonatal mortality statistics for all live births between 500 and $1499 \mathrm{~g}$ birth weight for 1993 and 1994 were obtained from statutory sources. $^{1-4}$

\section{STATISTICAL ANALYSES}

Multiple logistic regression analysis was undertaken using hospital mortality and hospital mortality or survival with cerebral damage as outcomes. Goodness of fit was assessed by the Hosmer Lemeshow $\chi^{2}$ statistic, ${ }^{18}$ for which $\mathrm{p}>0.05$ indicates satisfactory fit. Discriminatory power was assessed by receiver operator characteristic analysis. ${ }^{19}$ Differences in proportions were tested by $\chi^{2}$ test, and differences between medians by the Kruskal-Wallis U test or Mann-Whitney test. 
Table 3 Observed and expected hospital deaths, and standardised mortality ratio for infants admitted to neonatal intensive care units in 1993 and 1994, adjusted for risk using CRIB and gestation

\begin{tabular}{llllrll}
\hline $\begin{array}{l}\text { Neonatal intensive care } \\
\text { units }\end{array}$ & $\begin{array}{l}\text { Observed } \\
\text { deaths }\end{array}$ & $\begin{array}{l}\text { Expected } \\
\text { deaths }\end{array}$ & $\begin{array}{l}\text { Total } \\
\text { infants }\end{array}$ & p Value & $\begin{array}{l}\text { Standardised mortality ratio } \\
\text { (observed/ expected deaths) }\end{array}$ & $95 \%$ CI \\
\hline Australian & 199 & 198.9 & 1475 & 0.994 & 1.00 & - \\
All Scottish & 167 & 114.58 & 848 & $<0.001$ & 1.46 & 1.29 to 1.63 \\
Scottish tertiary & 142 & 94.67 & 718 & $<0.001$ & 1.50 & 1.31 to 1.69 \\
Scottish non-tertiary & 25 & 19.91 & 130 & 0.254 & 1.26 & 0.85 to 1.66 \\
\hline
\end{tabular}

A logistic regression model predicting hospital mortality was fitted using CRIB and gestation as explanatory variables in infants admitted to Australian neonatal intensive care units only. The model was then used to calculate the number of deaths expected in all Scottish neonatal intensive care units, and in Scottish tertiary and non-tertiary neonatal intensive care units respectively, using the Australian neonatal intensive care units as a reference. Significantly more deaths were observed in all Scottish neonatal intensive care units than in Australian neonatal intensive care units. Similarly significantly more deaths were observed in Scottish tertiary neonatal intensive care units than in Australian neonatal intensive care units. Mortality rates in Scottish tertiary and non-tertiary neonatal intensive care units were similar.

\section{Results}

STUDY 1

Table 1 describes hospital and clinical characteristics for the 2612 VLBW or preterm infants admitted to the study NICUs. Unadjusted hospital mortality was significantly higher in Scotland $(22 \%)$ than in Australia (13\%). Among all VLBW infants, the proportions of extremely low birthweight (500-999 g) infants were similar in the study cohort and each country (table 2). The average annual numbers of VLBW (500-1499 g) infants admitted per study NICU were 51 in Scotland and 121 in Australia. Both were more than the maximum possible average number admitted per NICU in all Scotland $(n=36)$ and Australia $(\mathrm{n}=104)$, but the ratios were similar between countries (51:36 $v 121: 104 ; \chi^{2}=0.59$, $\mathrm{p}=0.441)$.

A multiple logistic model was fitted by forward stepwise conditional regression, with hospital mortality as the dependent variable and CRIB, gestation, hospital type (Scottish tertiary NICU, Scottish non-tertiary NICU, or Australian NICU), and country of care as explanatory variables. All these variables except hospital type were independently associated with mortality, with no interactions between them and the model achieving satisfactory goodness of fit (table 3). The receiver operator characteristic curve area was 0.88 . When CRIB was omitted, the model did not achieve satisfactory goodness of fit.

Australian NICUs were used as a reference by fitting models for hospital mortality using CRIB and gestation, and gestation alone, in Australian infants only. Adjusted hospital mortality was then calculated as the ratio of observed to predicted mortality using those models in all Scottish NICUs and in nontertiary and tertiary Scottish NICUs separately. Mortality in Scottish NICUs was $46 \%$ higher than in Australian NICUs, adjusting for
CRIB and gestation (table 3), and 69\% higher adjusting for gestation alone (table 4). Adjusted mortality remained higher in Scottish NICUs after counting missing outcomes in Scotland as survivors and in Australia as deaths. Adjusted mortality was similar in Scottish tertiary and non-tertiary NICUs (tables 3 and 4). Compared with Australian NICUs, mortality in Scottish non-tertiary NICUs was not significantly higher after adjustment for CRIB and gestation (table 3), but was $61 \%$ higher after adjustment for gestation alone (table 4). The odds of hospital mortality in the whole cohort were twice as high in Scotland as in Australia (odds ratio 2.1, 95\% confidence interval (CI) 1.6 to 2.8) and remained higher in Scotland in a cohort of 1803 infants which was obtained after excluding all those of less than 28 weeks' gestation (odds ratio 1.9, 95\% CI 1.2 to 2.9 ).

A separate multiple regression model was then fitted, relating the composite variable of hospital death or survival with major cerebral damage to gestation, CRIB, and country. This had satisfactory goodness of fit (Hosmer Lemeshow $\chi^{2}=4.21,8 \mathrm{df}, \mathrm{p}=0.84$ ), with no interaction between explanatory variables. After adjustment for CRIB and gestation, the odds of death or survival with major cerebral damage were twice as high in Scottish as in Australian NICUs (odds ratio 1.9, 95\% CI 1.5 to 2.5). The odds of death or survival with major brain damage remained higher in Scotland in the cohort of 1803 infants obtained after excluding those of less than 28 weeks' gestation (odds ratio $2.0,95 \%$ CI 1.4 to 2.8 ).

STUDY 2

Table 5 shows that neonatal mortality was higher in Scotland (20.3\%) than Australia (16.6\%) among all 5986 infants 500-1499 g birth weight (relative risk 1.22, 95\% CI 1.08 to

Table 4 Observed and expected hospital deaths, and standardised mortality ratio for infants admitted to intensive care units in 1993 and 1994, adjusted for risk using gestation alone

\begin{tabular}{lllcrll}
\hline $\begin{array}{l}\text { Neonatal intensive care } \\
\text { unit }\end{array}$ & $\begin{array}{l}\text { Observed } \\
\text { deaths }\end{array}$ & $\begin{array}{l}\text { Expected } \\
\text { deaths }\end{array}$ & $\begin{array}{l}\text { Total } \\
\text { infants }\end{array}$ & p Value & $\begin{array}{l}\text { Standardised mortality ratio } \\
\text { (observed/ expected deaths) }\end{array}$ & $95 \%$ CI \\
\hline Australian & 216 & 215.83 & 1628 & 0.991 & 1.00 & - \\
All Scottish & 205 & 121.58 & 923 & $<0.001$ & 1.69 & 1.52 to 1.85 \\
Scottish tertiary & 172 & 101.12 & 775 & $<0.001$ & 1.70 & 1.52 to 1.88 \\
Scottish non-tertiary & 33 & 20.46 & 148 & 0.006 & 1.61 & 1.21 to 2.02 \\
\hline
\end{tabular}

A logistic regression model predicting hospital mortality was fitted using gestation as the explanatory variable in infants admitted to Australian neonatal intensive care units only. The model was then used to calculate the number of deaths expected in all Scottish neonatal intensive care units, and in Scottish tertiary and non-tertiary neonatal intensive care units respectively, using the Scottish neonatal intensive care units, and in Scottish tertiary and non-tertiary neonatal intensive care units respectively, using the
Australian neonatal intensive care units as a reference. As in table 3, significantly more deaths were observed in Scottish neonatal intensive care units than in Australian neonatal intensive care units. Hence early treatment bias- that is, inappropriate early intensive care units than in Australian neonatal intensive care units. Hence early treatment bias-that is, inappropriate early
treatment leading to inappropriately increased initial illness severity in Australia-is unlikely to explain the excess mortality treatment leading to
observed in table 3 . 
Table 5 Neonatal mortality for very low birthweight infants in Scotland, Australia, England and Wales $1993-96$

\begin{tabular}{|c|c|c|c|c|c|c|c|c|c|}
\hline & \multicolumn{4}{|c|}{$500-999 \mathrm{~g}$} & \multicolumn{3}{|c|}{$1000-1499 \mathrm{~g}$} & \multicolumn{2}{|l|}{$500-1499 \mathrm{~g}$} \\
\hline & \multicolumn{2}{|l|}{ Deaths } & \multicolumn{2}{|c|}{$\begin{array}{l}\text { Death ratel } \\
1000 \text { live births }\end{array}$} & \multicolumn{2}{|c|}{ Deaths } & $\begin{array}{l}\text { Death ratel } \\
1000 \text { live births }\end{array}$ & Deaths & $\begin{array}{l}\text { Death ratel } \\
1000 \text { live births }\end{array}$ \\
\hline Scotland 1993 & \multicolumn{2}{|c|}{$81 / 217$} & \multicolumn{2}{|l|}{373.3} & \multicolumn{2}{|c|}{$32 / 345$} & 92.8 & $113 / 562$ & 201.1 \\
\hline Scotland 1994 & \multicolumn{2}{|c|}{$110 / 241$} & \multicolumn{2}{|l|}{456.4} & \multicolumn{2}{|c|}{$24 / 413$} & 58.1 & $134 / 654$ & 204.9 \\
\hline Scotland 1993-1994 & \multicolumn{2}{|c|}{$191 / 458$} & \multicolumn{2}{|l|}{417.0} & \multicolumn{2}{|c|}{$56 / 758$} & 73.9 & $247 / 1216$ & 203.1 \\
\hline Scotland 1995 & \multicolumn{2}{|c|}{$94 / 170$} & \multicolumn{2}{|l|}{552.1} & \multicolumn{2}{|c|}{$32 / 399$} & 80.2 & $126 / 569$ & 221.4 \\
\hline Scotland 1996 & \multicolumn{2}{|c|}{$87 / 175$} & \multicolumn{2}{|l|}{497.1} & \multicolumn{2}{|c|}{$26 / 409$} & 63.6 & $113 / 584$ & 193.5 \\
\hline Scotland all years & \multicolumn{2}{|c|}{$372 / 803$} & \multicolumn{2}{|l|}{463.3} & \multicolumn{2}{|c|}{$114 / 1566$} & 2.8 & $486 / 2369$ & 205.1 \\
\hline Australia 1993 & $286 / 91$ & & 313.6 & & $99 / 1$ & 460 & 7.9 & $385 / 2372$ & 162.3 \\
\hline Australia 1994 & $324 / 90$ & & 356.8 & & $82 / 1$ & 490 & 5.0 & $406 / 2398$ & 169.3 \\
\hline Australia 1993-1994 & $610 / 18$ & & 335.2 & & $181 /$ & 2950 & 1.4 & $791 / 4770$ & 165.8 \\
\hline Australia 1995 & $332 / 94$ & & 352.4 & & $74 / 1$ & 396 & 3.0 & $406 / 2338$ & 173.7 \\
\hline Australia 1996 & $260 / 10$ & & 280.2 & & $54 / 1$ & 360 & 9.7 & $314 / 2437$ & 128.8 \\
\hline Australia all years & $1202 / 3$ & 839 & 313.1 & & $309 /$ & 15706 & 4.2 & $1511 / 9545$ & 158.3 \\
\hline England and Wales 1993* & $1035 / 2$ & 537 & 408.0 & & $308 /$ & 4176 & 3.8 & $1343 / 6713$ & 200.1 \\
\hline England and Wales $1994^{\star}$ & $1050 / 2$ & 855 & 367.8 & & 317 & 4429 & 1.6 & $1367 / 7284$ & 187.7 \\
\hline England and Wales 1993-1994* & $2085 / 5$ & 392 & 386.7 & & $625 /$ & 8605 & 2.6 & $2710 / 13997$ & 193.6 \\
\hline England and Wales 1995^ & $1124 / 2$ & 879 & 390.4 & & $301 /$ & 4704 & 4.0 & $1425 / 7583$ & 187.9 \\
\hline England and Wales $1996^{\star}$ & $1278 / 3$ & 150 & 405.7 & & $282 /$ & 4770 & 9.1 & $1560 / 7920$ & 197.0 \\
\hline England and Wales all years* & $4487 / 1$ & 1421 & 392.9 & & 1208 & $8 / 18079$ & 6.8 & $5695 / 29500$ & 193.1 \\
\hline In England and Wales neonata & & & & 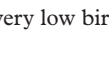 & & infant & - & info & $\mathrm{h}$ \\
\hline $\begin{array}{l}\text { Table } 6 \text { Relative risk of neona } \\
\text { with Australia }\end{array}$ & al deat & $h$ for 2 & ry low & birthweigh & & fants in Scotl & and and Englc & and and Wales & compared \\
\hline & & $500-5$ & $99 g$ & & & $1000-1499 g$ & & $500-1499 \mathrm{~g}$ & \\
\hline & & $\begin{array}{l}\text { Relat } \\
\text { of neo } \\
\text { death }\end{array}$ & $\begin{array}{l}\text { ve risk } \\
\text { natal }\end{array}$ & $\begin{array}{l}95 \% \\
\text { confidence } \\
\text { interval }\end{array}$ & & $\begin{array}{l}\text { Relative risk } \\
\text { of neonatal } \\
\text { death }\end{array}$ & $\begin{array}{l}95 \% \\
\text { confidence } \\
\text { interval }\end{array}$ & $\begin{array}{l}\text { Relative risk } \\
\text { of neonatal } \\
\text { death }\end{array}$ & $\begin{array}{l}95 \% \\
\text { confidence } \\
\text { interval }\end{array}$ \\
\hline Scotland $v$ Australia 1993 to 94 & & 1.32 & & 1.12 to 1. & & 1.17 & -1.49 & 1.22 & 1.08 to 1.39 \\
\hline Scotland $v$ Australia 1993 to 96 & & 1.48 & & 1.35 to 1 . & & 1.25 & 1.06 to 1.47 & 1.30 & 1.18 to 1.42 \\
\hline England and Wales $v$ Australia 199 & 3 to 94 & 1.06 & & 1.03 to 1. & & 1.05 & 1.01 to 1.09 & 1.05 & 1.03 to 1.07 \\
\hline England and Wales $v$ Australia & 3 to 96 & 1.09 & & 1.07 to 1 . & & 1.05 & 1.02 to 1.08 & 1.07 & 1.06 to 1.08 \\
\hline
\end{tabular}

1.39) registered in both countries. There were non-significant trends to increased neonatal mortality in Scotland for infants of 500-999 g and $1000-1499 \mathrm{~g}$ birth weight.

In further comparisons which were not planned in advance, population based neonatal mortality was obtained for VLBW infants in England and Wales in 1993 and 1994, and in Scotland, Australia, England and Wales in 1995 and 1996 using data from statutory sources (tables 5 and 6 ).

\section{Discussion}

STUDY 1

After adjustment for risk, rates of mortality and mortality or survival with cerebral damage were greater in Scottish than in Australian NICUs in this sample. Whereas comparisons of mortality in adult and paediatric intensive care are considered invalid without adjusting for clinical risk and illness severity, ${ }^{20-25}$ comparisons of mortality in neonatal intensive care have traditionally been adjusted only for birth weight or gestation, which predict risk of mortality less accurately than models that include illness severity. ${ }^{9-14}$ 26-31 Furthermore, birthweight specific and gestation specific hospital death rates are less valid indicators of NICU performance, as they are more influenced by events before birth. ${ }^{29-32}$ We addressed these issues by adjusting hospital mortality for gestation and CRIB.

Caution is required in interpreting the results because these NICUs were not randomly selected and they admitted more than the average numbers of VLBW infants for both countries. However, their case mix, as measured by birth weight, was nationally representative (table 2) and they accounted for about $75 \%$ of all high risk infants admitted in Scotland, over $95 \%$ in Queensland, and nearly $50 \%$ in New South Wales during the study period. Compared with that in Scottish and Australian tertiary NICUs, adjusted mortality was not significantly different in Scottish nontertiary NICUs, but this may reflect the small sample size and wide confidence intervals (tables 3 and 4). Scottish tertiary NICUs showed a trend to higher risk adjusted mortality than Scottish non-tertiary NICUs after adjustment for CRIB and gestation, but this was not statistically significant. However, a true excess mortality in tertiary hospitals is not inconceivable. Larger nationally representative studies of hospital outcome in relation to volume, staffing policy, and workload are needed. ${ }^{33-35}$ As median CRIB scores in Scottish and Australian NICUs were similar (table 2), their patients' mortality risk was similar soon after birth, having accounted for prior risk and treatment, such as antenatal steroids, neonatal resuscitation, early surfactant treatment, and neonatal care up to 12 hours from birth. Therefore the lower risk adjusted mortality in Australia is consistent with more effective neonatal care after 12 hours after birth.

Our study was designed to impose as little extra work as possible by collecting only a minimum of data. We did not therefore request information about transfers between hospitals before or after birth or the number of liveborn infants after 20 weeks' gestation who died without admission to neonatal units, or who were admitted to neonatal units for comfort 
care only. Previous work showed no difference in outcome between postnatally transferred and inborn infants after adjusting for clinical risk and initial severity of illness. ${ }^{9}$ However, as variations in admission policy for very immature infants may lead to selection bias, ${ }^{36}$ we compared risk adjusted hospital mortality and the composite outcome of mortality or cerebral damage after excluding infants of less than 28 weeks' gestation. Both risk adjusted adverse outcomes remained more common in Scottish than Australian NICUs.

Rates of cerebral damage or disability may not reflect the quality of NICU care, as the timing of cerebral damage leading to disability is often unclear. For example, by salvaging infants whose brains are damaged before birth, effective neonatal care may push up, not reduce, the prevalence of disability. ${ }^{37-39}$ In previous studies, CRIB has been associated with cerebral haemorrhage before discharge ${ }^{9}$ and with death or disability in survivors at 18 months. ${ }^{39}$ If we assume that the proportion of preterm infants sustaining postnatally determined brain damage was similar in each country, then the lower rate of cerebral damage in Australian NICUs after adjustment for CRIB and gestation is further evidence of better NICU performance.

STUDY 2

If NICUs were generally less effective in Scotland than Australia, we predicted that population based neonatal mortality for all infants of 500-1499 g birth weight would also be higher in Scotland. Table 5 supports that prediction. An alternative explanation for the difference in neonatal mortality may be differences in accuracy of ascertainment and completeness of registration, particularly for extremely immature infants at the edge of viability. However, definitions of live births and statutory requirements for registration are similar in both countries and a trend to greater survival in Australia was also seen in infants of 1000-1499 g birth weight, in whom failure to be registered as live born is less likely.

In further analyses, population based neonatal mortality in infants of less than $1500 \mathrm{~g}$ birth weight was also lower in Australia than in England and Wales during the study period 19931994. The same was true for Australia compared with Scotland and England and Wales in 1995 and 1996, and for all four years combined (table 5). These differences in neonatal outcome were therefore not transient. The inclusion of infants of less than $500 \mathrm{~g}$ may have disadvantaged England and Wales somewhat in these comparisons, but the same pattern of difference in mortality between the three populations was also seen for infants of 1000-1499 g birth weight.

How else could the overall findings be explained? An ideal system for risk adjustment would reliably assess total risk and illness severity at birth or NICU admission. ${ }^{29}$ As this is not practicable, illness severity is measured from data soon afterwards, reflecting the infant's intrinsic condition and prior treatment, hence the possibility of "lead time bias" or "early treatment bias". Units that increase their infants' illness severity by poor early treatment may decrease their risk adjusted mortality compared with those that improve early illness severity. ${ }^{97} 29$ If Australian NICUs made their infants more ill or Scottish NICUs did the opposite, this lead time or early treatment bias $^{40}$ may explain the increased risk adjusted mortality in Scottish NICUs. However, that explanation is unlikely, as hospital mortality remained higher in Scottish NICUs when adjusted for gestation alone (table 4). Another improbable explanation is that the NICUs in this study are unrepresentative of all Australian NICUs, whose true level of performance is equal to or worse than that of Scottish NICUs. If this were so, the excess 28 day neonatal mortality reported in Scotland would need to be attributed to less effective obstetric and early neonatal care in Scotland than Australia.

Can the better outcomes in Australia be attributed entirely to genetic, social, or environmental factors? This is also unlikely. Between 1985 and 1994, stillbirths and deaths in the first month in Australia fell from 11.8 to 8.0 per 1000 births, ${ }^{41}$ while stillbirths and deaths in the first week in Scotland fell from 9.8 to 7.4 per 1000 births. ${ }^{4}$ These trends are more likely to reflect rapid advances in obstetric and neonatal care rather than genetic, socioeconomic, or environmental improvement. Furthermore, although the risk of being of very low birth weight may increase with lower social class, ${ }^{42}$ it is not clear that, within the lower social class group, mortality is related to social class independently of birth weight, gestation, or illness severity. The findings are also unlikely to reflect differences in the scoring of congenital malformations, as these were coded in ignorance of each infant's nationality.

We conclude that neonatal intensive care was more effective in this sample of Australian NICUs, echoing a recent international comparison of paediatric intensive care, ${ }^{25} 40$ and that neonatal mortality was lower in Australia. These findings may be consistent, at least in part, with differences in the organisation of neonatal services, such as greater specialisation of medical and nursing staff, or higher nurse/patient ratios, or with differences in speed of implementation of effective treatment. ${ }^{43}$ If substantial increases in the daily volume of patients are associated with more effective care ${ }^{44}$ the substantially greater numbers of patients treated by Australian NICUs may also be important.

Although these findings may focus attention on perinatal and neonatal services in Scotland and England and Wales, there is no room for inertia in Australia, or elsewhere. Few countries collect national data on mortality and disability after neonatal intensive care. Given the potential burden on families and high costs to society, this seems illogical. We suggest that neonatal and postneonatal deaths in infants admitted to NICUs should be linked with measures of early illness severity, so that population based risk adjusted rates of NICU mortality can be monitored. Effective systems for 
monitoring the rate of major disability in survivors are also needed ${ }^{45}$ and may be feasible at relatively little cost. ${ }^{46}$ These initiatives could help in planning for future demand for paediatric services and in building a framework for large randomised trials to track outcomes and test promising strategies for prevention. ${ }^{47-49}$

This work was funded by the Scottish Office Home and Health Department and Clinical Resource and Audit Group, Wellcome
Trust, Action Research, Medical Research Council, and NHS Trust, Action Research, Medical Research Council, and NHS
Executive Mother and Child Health Programme. The Medical Research Council cited the CRIB score as a scientific Research Council cited the CRIB score as a scientific achievement in 1994. We thank all the neonatal nursing and audit coordinators in each unit for providing prospective data We thank Samantha Paterson of the Information and Statistics Division, Common Services Agency, Edinburgh for additional Scottish data and Deborah Donoghue, Paul Lancaster, and James King for additional Australian data and helpful criticism.
We thank Jeremy Schuman, Office of National Statistics, for data on England and Wales.

Principal contributors on behalf of the International Neonatal Network and Scottish Neonatal Nurses and Consultants Collaborative Study Group (writing committee ${ }^{\star}$ ): William Tarnow-Mordi ${ }^{\star}$, Craig Gould ${ }^{\star}$, Gareth Parry ${ }^{\star}$, Karen Hamilton ${ }^{\star}$, Neil McIntosh ${ }^{\star}$, David Henderson Smart ${ }^{\star}$, Andrew Gill, Naomi Rynne, Elizabeth John, Marilyn Rochefort, Graham Reynolds, David Tudehope, Peter Gray, David Cartwright, Paul Colditz, Ian Laing, Chris Steer, Alastair Blair, Tom Turner, Barbara Holland, Charles Skeoch, Forrester Cockburn, Layla Alroomi, Paul Galea, Dominic Cochran, Ann Glen, Pat Weir, Ann Sutton, John McDonald, Susan Barclay, George Farmer, Paul Duffty, David Lloyd, Philip Booth, Stewart Forsyth, Peter Fowlie, Janet Tucker, Diana Caborn, Brenda Massie, Denise Strang, Sylvia Newton.

1 Information and Statistics Division. Scottish stillbirth and neonatal death report 1993. St Andrew's House, Edinburgh: Scottish Health Service Common Services Agency, 1994.

2 Information and Statistics Division. Scottish stillbirth and neonatal death report 1994. St Andrew's House, Edinburgh
Scottish Health Service Common Services Agency, 1995.

3 Lancaster P, Huang J, Lin M. Australia's mothers and babies 1993. Perinatal statistics series no 3. Australian Institute of 1993. Perinatal statistics series

4 Day P, Lancaster P, Huang J. Australia's mothers and babies 1994. Perinatal statistics series no 3. Australian Institute of Health and Welfare, 1995.

5 Donoghue DA. Australian and New Zealand neonatal network, 1995. Sydney: Australian Institute of Health and Welfare National Perinatal Statistics Unit: Neonatal Network Series No 2, 1997

6 British Association of Perinatal Medicine. Standards for hospitals providing neonatal intensive care. British Association of Perinatal Medicine, 1996.

7 Northern Neonatal Network. Measuring neonatal nursing workload. Arch Dis Child 1993;68:539-43.

8 Australian Health Ministers' Advisory Council: Superspecialty Services Subcommittee. Guidelines for level three neo-
natal intensive care. Canberra: Australian Institute of Health, 1991.

9 International Neonatal Network. The CRIB (clinical risk index for babies) score: a tool for assessing initial neonatal
risk of mortality and comparing performance of neonatal risk of mortality and comparing performance
intensive care units. Lancet 1993;342:193-8.

10 Rautonen J, Makela A, Boyd H, Apajasalo M, Pohjavuori $M$. CRIB and SNAP: assessing the risk of death for preterm neonates. Lancet 1993;343:1272-3.

11 De Courcy Wheeler RHB, Wolfe CDA, Fitzgerald A, Spencer M, Goodman JDS, Gamsu HR. Use of the CRIB (clinical risk index for babies) score in prediction of Neonatal Ed 1995;73:F32-6.

12 Fowlie PW, Gould CR, Parry G, Phillips G, Tarnow-Mordi WO. CRIB (clinical risk index for babies) in relation to nosocomial bacteraemia in very low birthweight infants. Arch Dis Child Fetal Neonatal Ed 1996;75:F49-52.

13 Baumer JH, Wright D, Mill T. Illness severity as measured by CRIB score: a product of changes in perinatal care? Arch Dis Child Fetal Neonatal Ed 1997;77:F211-15.

14 Kaaresen PI, Døhlen G, Fundingsrud HP, Dahl LB. The use of CRIB (Clinical Risk Index for Babies) score in auditing the performance of one neonatal intensive care unit. Acta Paediatr Scand 1998;87:153-9.

15 Emsley HCA, Wardle SP, Sims DG, Chiswick ML, D’Souz SW. Increased survival and deteriorating developmenta outcome in 23 to 25 week old gestation infants, 1990-4 compared with 1984-9. Arch Dis Child Fetal Neonatal Ed 1998;78:F99-104.

16 Crowley P, Chalmers I, Keirse MJNC. The effect of corticosteroid administration before preterm delivery: an overview of the evidence from controlled trials. Br f Obstet Gynaecol 1990;97:1-25.

17 Rennie JM, Wheater M, Cole TJ. Antenatal steroid administration is associated with an improved chance of intact survival in preterm infants. Eur 7 Pediatr 1996;155:576-9.

18 Hosmer DW, Lemeshow S. Applied logistic regression. New York: John Wiley and Sons, 1989.
19 Hanley JA, McNeil BJ. A method of comparing the areas under the receiver operator characteristic curves derive from the same patients. Radiology 1983;148:839-43.

20 Knaus WA, Wagner DP, Draper EA, et al. The APACHE III prognostic system. Risk prediction of hospital mortality for critically ill hospitalized adults. Chest 1991;100:1619-36.

21 Rowan KM, Kerr JH, Major E, McPherson K, Short A, Vessey MP. Intensive Care Society's APACHE II study in Britain and Ireland. II. Outcome comparisons of intensive care units after adjustment for case mix by the American APACHE II method. BMF 1993;307:977-81.

22 Le Gall JR, Lemeshow S, Saulnier F. A new simplified acute physiology score (SAPS II) based on a European/North American multicenter study. $\mathscr{F} A M A$ 1993;270:2957-63.

23 Pollack MM, Patel KM, Ruttimann UE. PRISM III: an updated pediatric risk of mortality score. Crit Care Med 1996;24:743-52.

24 Shann F, Pearson G, Slater A, Wilkinson K. Paediatric index of mortality (PIM): a mortality prediction model for children in intensive care. Intensive Care Med 1997;23:201-7.

25 Pearson G, Shann F, Barry P, et al. Should paediatric intensive care be centralised? Trent versus Victoria. Lancet 1997;349:1213-17.

26 Gray JE, Richardson DK, McCormick MC, et al. Birthweight and illness severity: independent predictors of NICU mortality. Pediatrics 1993;91:969-75.

27 Tarnow-Mordi WO, Ogston SA, Wilkinson AR, et al. Predicting death from initial disease severity in very low birthweight infants: a method for comparing performance of neonatal units. BMF 1990;300:1611-14.

28 Maier RF, Rey M, Metze BC, Obladen M. Comparison of mortality risk: a score for very low birthweight infants. Arch Dis Child Fetal Neonatal Ed 1997;76:F146-50.

29 Maier RF, Rey M, Metze BC, Obladen M. Comparison of mortality risk: a score for very low birthweight infants. [Tarnow-Mordi W, commentary]. Arch Dis Child Fetal Neonatal Ed 1997;76:F146-51.

30 Tarnow-Mordi WO, Cooke RWI, Parry GJ, Ogston SA. The CRIB score. Lancet 1993;342:613.

31 Richardson DK, Tarnow-Mordi WO. Neonatal illness severity and new insights into perinatal audit. Acta Paediatr 1998;87:134-5.

32 Richardson DK, Shah BL, Frantz ID, Bednarek F, Rubin LP, McCormick MC. Perinatal risk and severity of illness in newborns at 6 neonatal

33 Tarnow-Mordi WO, Tucker JS, McCabe CJ, Nicolson P, Parry GJ. The UK neonatal staffing study: a prospective evaluation of neonatal intensive care in the United Kingdom. Seminars in Neonatalology 1997;2:171-9.

34 Tarnow-Mordi W, Tucker J, Parry G, McCabe C, Nicolson $\mathrm{P}$, for the UK Neonatal Staffing Study Collaborative Group. Protocol P7/18: The UK neonatal staffing study: a prospective evaluation of risk-adjusted outcomes of prospective evaluation of risk-adjusted outcomes of
neonatal intensive care in relation to volume, staffing, and neonatal intensive care in relation to volume, staffing, and workload.

35 The UK Neonatal Staffing Study Website. http:// www.Child-health.dundee.ac.uk/research/UKNeonatalStaffing/ [accessed 1 October 1999].

36 Field D, Draper ES. Survival and place of delivery following preterm birth: 1994-96. Arch Dis Child Fetal Neonatal Ed 1999;80:F111-17.

37 Pharoah POD. CRIB and impairment after neonatal intensive care. Lancet 1995;346:58.

38 Tarnow-Mordi W, Mutch L, Parry G, Cockburn F, McIntosh N. CRIB and impairment after neonatal intensive care. Lancet 1995;346:58-9.

39 Scottish Neonatal Consultants' Collaborative Study Group and the International Neonatal Network. CRIB (clinical risk index for babies), mortality, and impairment after neonatal intensive care. Lancet 1995;345:1020-2.

40 Tarnow-Mordi WO, Tucker J, Parry G. Should paediatric intensive care be centralised? Lancet 1997;350:66-7.

41 Australian Institute of Health and Welfare. Australia's health. Sydney: AIHW Publications, 1997

42 Office for National Statistics. Series DH3 no 27. Mortality statistics: childhood, infant and perinatal. Review of the RegisLondon: The Stationery Office, 1995.

43 Scottish Neonatal Consultants Collaborative Study Group and International Neonatal Network. Trends and variations in use of antenatal corticosteroids to prevent neonatal respiratory distress syndrome. Recommendations for national and international comparative audit. Br f Obstet Gynaecol 1996;103:534-40.

44 Phibbs CS, Bronstein JM, Buxton E, Phibbs RH. The effects of patient volume and level of care at the hospital of birth on neonatal mortality. $\mathcal{F A M A} 1996 ; 276: 1054-9$.

45 Johnson A. Follow up studies: a case for a standard minimum data set. Arch Dis Child Fetal Neonatal Ed 1997;76:F61-3

6 Dawson C, Perkins M, Draper E, Johnson A, Field D. Are outcome data regarding the survivors of neonatal care available from routine sources? Arch Dis Child Fetal Neonatal Ed 1997;77:F206-10

47 Taylor D, Kenyon S, Tarnow-Mordi W. Infection and preterm labour. Br f Obstet Gynaecol 1997;104:1338-40.

48 Lees C, Campbell S, Jauniaux S, et al. Arrest of preterm labour and prolongation of pregnancy with glyceryl
trinitrate, a nitric oxide donor. Lancet 1994;343:1324-5.

49 Kinmond S, Aitchison TC, Holland BM, Jones JG, Turner TL, Wardrop CAJ. Umbilical cord clamping in preterm infants: a randomised trial. BMF 1993;306:172-5. 